University of Nebraska - Lincoln

DigitalCommons@University of Nebraska - Lincoln

May 2003

\title{
Magnetic properties of $L 1_{0} \mathrm{FePt}$ and FePt:Ag nanocluster films
}

Yinfan Xu

University of Nebraska - Lincoln, yxu2@unl.edu

Zhiguang Sun

University of Nebraska - Lincoln, zsun3@unl.edu

Y. Qiang

University of Nebraska - Lincoln

David J. Sellmyer

University of Nebraska-Lincoln, dsellmyer@unl.edu

Follow this and additional works at: https://digitalcommons.unl.edu/physicssellmyer

Part of the Physics Commons

Xu, Yinfan; Sun, Zhiguang; Qiang, Y.; and Sellmyer, David J., "Magnetic properties of $L 1_{0}$ FePt and FePt:Ag nanocluster films" (2003). David Sellmyer Publications. 29.

https://digitalcommons.unl.edu/physicssellmyer/29

This Article is brought to you for free and open access by the Research Papers in Physics and Astronomy at DigitalCommons@University of Nebraska - Lincoln. It has been accepted for inclusion in David Sellmyer Publications by an authorized administrator of DigitalCommons@University of Nebraska - Lincoln. 


\title{
Magnetic properties of $\mathrm{L}_{0} \mathrm{FePt}$ and FePt:Ag nanocluster films
}

\author{
Yingfan $\mathrm{Xu},{ }^{\text {a) }}$ Z. G. Sun, Y. Qiang, and D. J. Sellmyer \\ Center for Materials Research and Analysis and Department of Physics and Astronomy, \\ University of Nebraska, Lincoln, Nebraska 68588-0113
}

(Presented on 15 November 2002)

\begin{abstract}
A sputtering gas-aggregation technique has been used to prepare FePt and FePt:Ag nanocluster films. The cluster size was controlled in a range from 3 to $6 \mathrm{~nm}$. FePt cluster films were directly deposited onto Si substrate; FePt:Ag cluster films were fabricated by depositing a FePt cluster layer between a Ag underlayer and overlayer. Nanostructure and magnetic properties of the samples were characterized by $\mathrm{x}$-ray diffraction, transmission electron microscopy, and magnetometry. The high magnetic anisotropy $\mathrm{L} 1_{0}$ fct phase was realized in the films annealed at a temperature of $550{ }^{\circ} \mathrm{C}$ and above. The orientation of clusters is random. The coercivity increases with an increase of annealing temperature; high in-plane and out-of-plane coercivities, exceeding $10 \mathrm{kOe}$, were achieved in both FePt and FePt:Ag cluster films after annealing. For FePt:Ag films, the coercivity increases with $\mathrm{Ag}$ underlayer thickness, $t_{\mathrm{Ag}}$, and reaches about $17 \mathrm{kOe}$ at room temperature for $t_{\mathrm{Ag}}=5 \mathrm{~nm}$ after annealing at $650{ }^{\circ} \mathrm{C}$ for $10 \mathrm{~min}$. The high coercivity is closely correlated with the degree of $\mathrm{L} 1_{0}$ ordering and nanostructure of the films. (C) 2003 American Institute of Physics.
\end{abstract}

[DOI: $10.1063 / 1.1556256]$

\section{INTRODUCTION}

In recent years there has been considerable interest in FePt nanoparticles with the high magnetic anisotropy $\mathrm{L}_{0}$ ordered structure for extremely high-density magnetic recording (EHDR) media. ${ }^{1-4}$ The requirement of noise reduction for extremely high magnetic recording density, e.g., from $100 \mathrm{~Gb} / \mathrm{in}^{2}$ to $1 \mathrm{~Tb} / \mathrm{in}^{2}$, imposes the need for grain size being reduced below $10 \mathrm{~nm}$ with extremely uniform size distribution. ${ }^{5}$ As a consequence, such small particles of the standard $\mathrm{CoCrPtX}$ type, will cause the thermal instability of magnetic recording because of superparamagnetic limitation. The equiatomic ordered face-centered-tetragonal (fct) phase FePt alloy has a high anisotropy constant, about 7 $\times 10^{7} \mathrm{erg} / \mathrm{cm}^{3}$, which is of crucial importance for EHDR media with a grain size below $10 \mathrm{~nm}$, because the reduction of grain size can be balanced by large anisotropy based on the thermal stability factor $K_{u} V / k_{B} T$. The high $K_{u} V$ value can create a barrier to thermally activated switching of the magnetization. Most FePt nanoparticles were prepared with normal magnetron sputtering or electron-beam-evaporation techniques. ${ }^{1-4}$ New techniques such as chemical synthesis and self-assembly methods have been developed recently to obtain FePt nanoparticles with very uniform particle size and narrow size distribution. ${ }^{6}$

In this article FePt clusters are produced with a gasaggregation technique, in which magnetron sputtering is employed in the source. ${ }^{7}$ This cluster-deposition technique can produce a very large range of mean cluster sizes from 200 to

${ }^{a)}$ Electronic mail: yxu2@unl.edu
15000 atoms per cluster with high fluxes. Thus it is suitable for preparation of FePt cluster-based materials. The success of this application may provide an alternative method for fabrication of extremely high-density magnetic recording
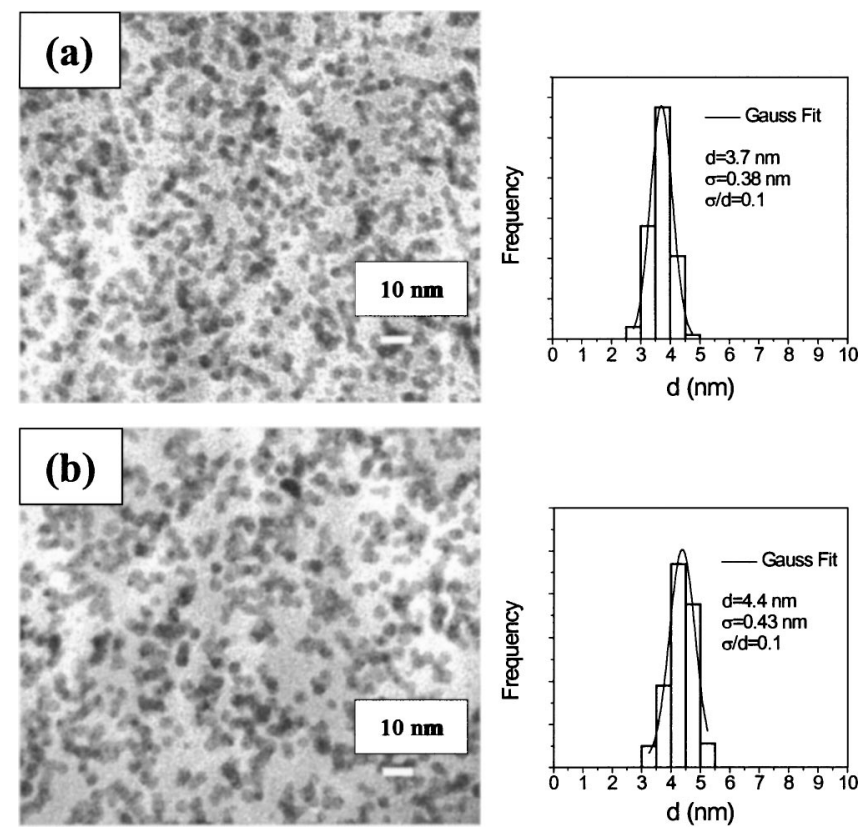

FIG. 1. TEM images of FePt nanoclusters: (a) deposited at power $60 \mathrm{~W}$ with $\mathrm{Ar} / \mathrm{He}$ gas flow 250/250 sccm; and (b) at power $100 \mathrm{~W}$ with $\mathrm{Ar} / \mathrm{He}$ gas flow $300 / 200 \mathrm{sccm}$. The right side shows the corresponding cluster size distribution. 


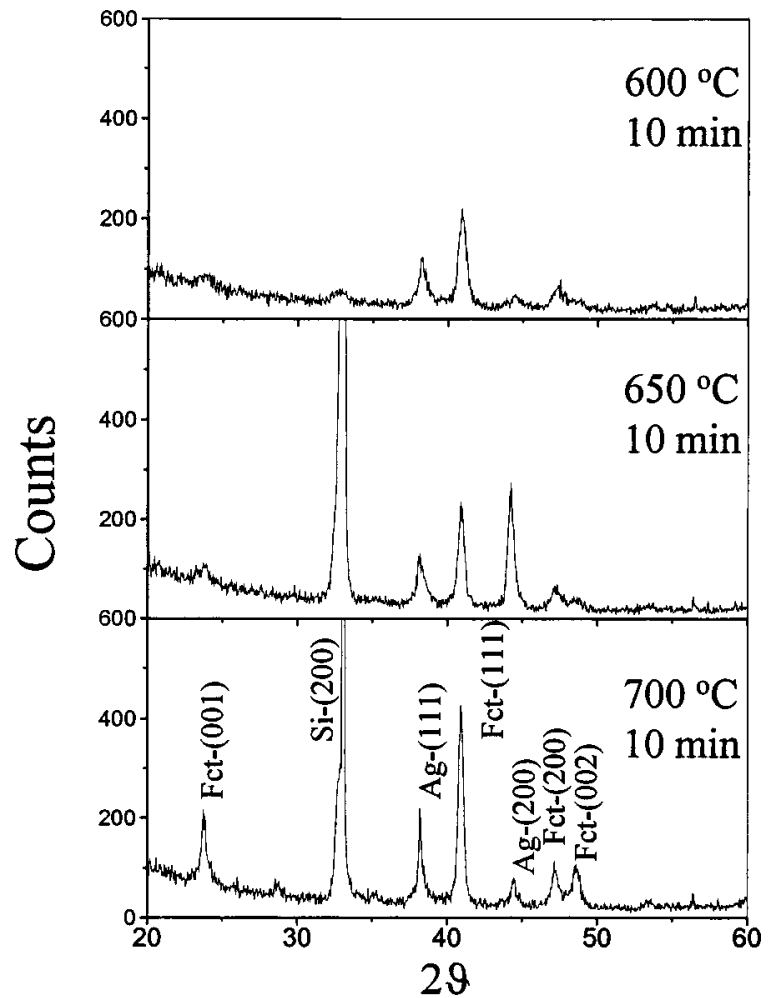

FIG. 2. XRD $(\theta-2 \theta)$ scans of $\operatorname{Ag}(2 \mathrm{~nm}) / \mathrm{FePt}(12 \mathrm{~nm}) / \mathrm{Ag}(2 \mathrm{~nm}) / \mathrm{Si}$ nanocluster films annealed at different temperature for $10 \mathrm{~min}$.

media or permit the exploration of other novel properties of nanocluster films.

\section{EXPERIMENT}

FePt and FePt:Ag cluster films are prepared using a cluster-deposition system with a sputtering gas-aggregation source. FePt clusters were formed in a $\mathrm{LN}_{2}$ cooled chamber filled with high pressure $\mathrm{Ar}-\mathrm{He}$ gas. Detail of the cluster deposition will be published elsewhere. ${ }^{8}$ The base pressure of the cluster-forming chamber was $<1 \times 10-{ }^{7}$ Torr. During deposition, the chamber was cooled below $-120^{\circ} \mathrm{C}$, and the $\mathrm{Ar}-\mathrm{He}$ pressure was about $5 \times 10^{-1}$ Torr. This high pressure restricted the glow discharge region to a few millimeters from the target, allowing the sputtered FePt atoms to grow into clusters in the cooled $\mathrm{Ar}-\mathrm{He}$ gas atmosphere by repeated collisions with the carrier gas.

FePt nanoclusters are directly deposited onto Si or 7059 glass substrates; FePt:Ag cluster films are deposited with a FePt cluster layer between a $\mathrm{Ag}$ underlayer and overlayer. The thickness of the FePt layer was varied from 12 to $15 \mathrm{~nm}$. The as-deposited films were annealed at various temperatures in a rapid thermal annealing (RTA) furnace in an Ar gas flow. Nanostructure of the films was examined with a Rigaku $\mathrm{x}$-ray diffractometer (XRD) using $\mathrm{Cu} K \alpha$ radiation and a JEOL 2010 transmission electron microscope (TEM). Magnetic properties were measured by a superconducting quantum interference device (SQUID).

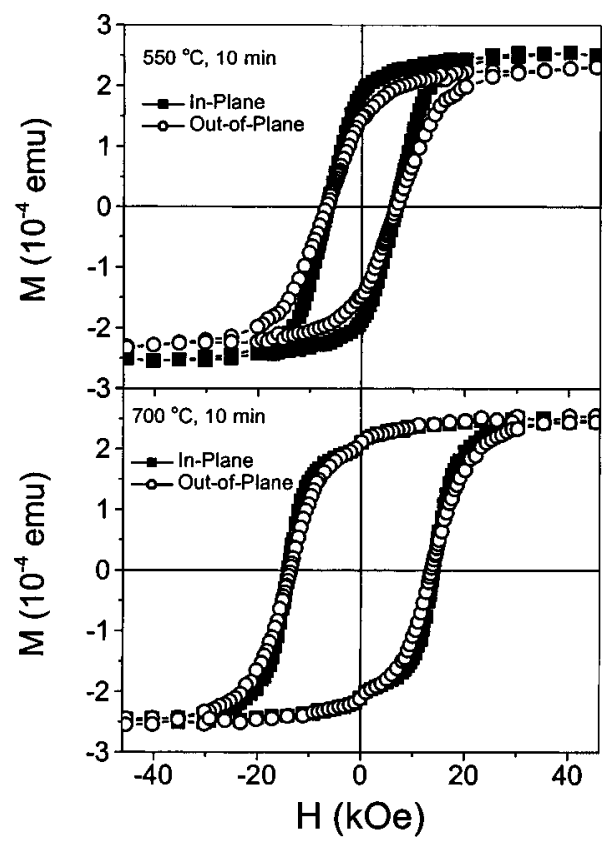

FIG. 3. Hysteresis loops of $\mathrm{FePt}(15 \mathrm{~nm}) / \mathrm{Si}$ nanocluster film annealed at 550 and $700{ }^{\circ} \mathrm{C}$ for $10 \mathrm{~min}$.

\section{RESULTS AND DISCUSSION}

Figure 1 shows the TEM images of FePt nanoclusters as deposited on carbon-coated films supported by $\mathrm{Cu}$ grids. Shown on the right-hand side is a corresponding cluster size distribution. Spherical clusters with an average size of 3.7 $\mathrm{nm}$ (standard deviation $\sigma=0.38 \mathrm{~nm}$ ) were prepared with sputtering power of $60 \mathrm{~W}$ and $\mathrm{Ar} / \mathrm{He}$ gas flow of 250/250 [Fig. 1(a)]; while clusters with size of $4.4 \mathrm{~nm}(\sigma$ $=0.43 \mathrm{~nm}$ ) were prepared with $100 \mathrm{~W}$ and gas flow of $300 /$ $200 \mathrm{sccm}$ [Fig. 1(b)]. The cluster size can be controlled in a range from 3 to $6 \mathrm{~nm}$ by adjusting the sputtering power and $\mathrm{Ar}-\mathrm{He}$ gas flow and gas pressure. The size distribution with $\sigma / d=0.1$ is fairly good, and can be further improved if desired by applying a mass selector. In the following sections the cluster films were prepared using power of $100 \mathrm{~W}$. XRD measurement confirmed the ordering of $\mathrm{L}_{0}$ structure by postannealing. Figure 2 shows the XRD $(\theta-2 \theta)$ scans of $\mathrm{Ag}(2 \mathrm{~nm}) / \mathrm{FePt}(12 \mathrm{~nm}) / \mathrm{Ag}(2 \mathrm{~nm}) / \mathrm{Si}$ cluster film annealed at

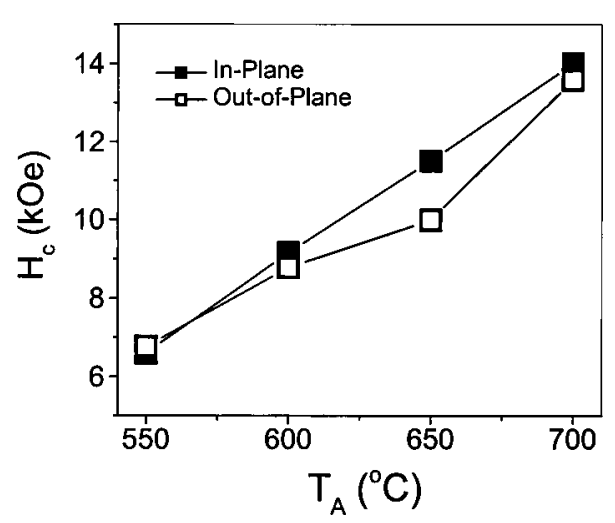

FIG. 4. Effect of annealing temperature on coercivity of $\mathrm{FePt}(15 \mathrm{~nm}) / \mathrm{Si}$ nanocluster films. Annealing time: $10 \mathrm{~min}$. 


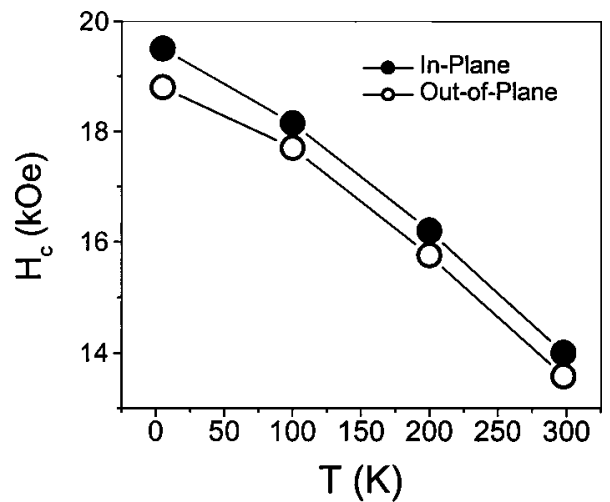

FIG. 5. Coercivity dependence on temperature for FePt(15 nm)/Si cluster film annealed at $700{ }^{\circ} \mathrm{C}$ for $10 \mathrm{~min}$.

600,650 , and $700{ }^{\circ} \mathrm{C}$ for $10 \mathrm{~min}$, respectively. The asdeposited film showed a broad FePt fcc (111) peak and $\mathrm{Ag}$ fcc (111) and (200) peaks. After annealing at $600{ }^{\circ} \mathrm{C}$ for 10 min, the FePt fct (001) and (002) peaks appeared, and the (200) and (002) peaks overlapped, indicating that the $\mathrm{L} 1_{0}$ ordering developed in the clusters, although was not completed. After annealing at $650^{\circ} \mathrm{C}$ for $10 \mathrm{~min}$, the (200) and (002) peaks were well separated, and the intensities of the fct peaks increased with increase of annealing temperature, indicating the $\mathrm{L} 1_{0}$ ordering was almost completed. In all the above films, the orientation of the fct FePt clusters is random.

Magnetic properties of the cluster films were measured by SQUID. Figure 3 shows the room temperature hysteresis loops of the $\mathrm{FePt}(15 \mathrm{~nm}) / \mathrm{Si}$ films annealed at 550 and $700{ }^{\circ} \mathrm{C}$ for $10 \mathrm{~min}$. Both in-plane ( $H \|$ film plane) and perpendicular ( $H \perp$ film plane) loops are presented. The perpendicular coercivity is almost the same as the in-plane coercivity, indicating that the easy axis of clusters is distributed randomly. This result is consistent with that obtained by XRD measurement (see Fig. 2). The degree of ordering depends on the annealing temperatures; large coercivity of the cluster films originated from the large $K_{u}$ of the fct phase. Figure 4 shows the effect of annealing temperature on coercivity of the cluster films. The coercivity exceeded $6 \mathrm{kOe}$ after annealing at $550^{\circ} \mathrm{C}$, indicating that most of FePt clusters have transformed into fct phase at this stage of annealing. The coercivity increases with increase of annealing temperature linearly, and high in-plane and out-of-plane coercivities, approaching $14 \mathrm{kOe}$, have been achieved after annealing at $700{ }^{\circ} \mathrm{C}$ for $10 \mathrm{~min}$. In order to determine the thermal effect on coercivity, the hysteresis loops of FePt cluster films were measured at low temperature down to $5 \mathrm{~K}$. Figure 5 shows the coercivity dependence on temperature for FePt (15 $\mathrm{nm}) / \mathrm{Si}$ cluster film from 5 to $300 \mathrm{~K}$. The film was annealed at $700{ }^{\circ} \mathrm{C}$ for $10 \mathrm{~min}$. The coercivity decreases with increase of measuring temperature, dropping from $19 \mathrm{kOe}$ at $5 \mathrm{~K}$ to

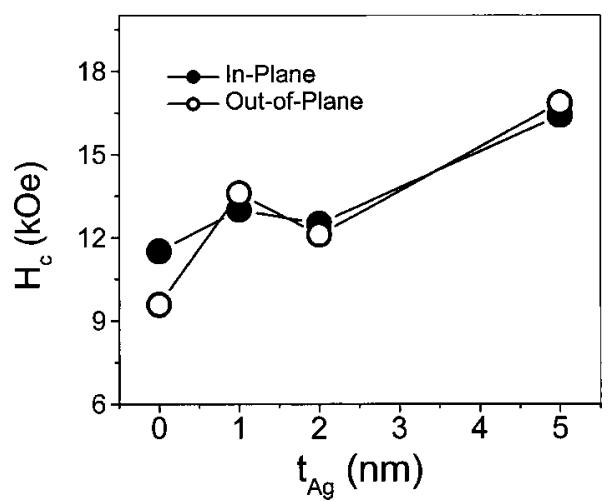

FIG. 6. Effect of $\mathrm{Ag}$ underlayer thickness on coercivity of $\mathrm{Ag} / \mathrm{FePt} / \mathrm{Ag}$ $(t \mathrm{~nm}) / \mathrm{Si}$ films annealed at $650{ }^{\circ} \mathrm{C}$ for $10 \mathrm{~min}$.

about $14 \mathrm{kOe}$ at $300 \mathrm{~K}$. This is caused by a contribution of intrinsic temperature dependence of the anisotropy and magnetization, and thermal activation effects. ${ }^{9}$ Coercivities of $\mathrm{Ag} / \mathrm{FePt} / \mathrm{Ag}$ films show a similar tendency with respect to annealing temperature and thermal effect. Figure 6 shows the effect of the Ag underlayer thickness on the coercivity of the $\mathrm{Ag} / \mathrm{FePt} / \mathrm{Ag}$ cluster films annealed at $650^{\circ} \mathrm{C}$ for $10 \mathrm{~min}$. The coercivity increased with increase of $\mathrm{Ag}$ underlayer thickness, and reached about $17 \mathrm{kOe}$ at room temperature as $\mathrm{Ag}$ underlayer thickness equals about $5 \mathrm{~nm}$. Compared with the coercivity of $14 \mathrm{kOe}$ for $\mathrm{FePt} / \mathrm{Si}$ film annealed at $700^{\circ} \mathrm{C}$ (see Fig. 4), this result suggests that addition of $\mathrm{Ag}$ underlayer can lower $\mathrm{L} 1_{0}$ ordering temperature and increase the coercivity of the cluster films significantly. It is likely that this results from the partial interdiffusion of the $\mathrm{Ag}$ underlayers and overlayers between and into the FePt clusters.

\section{ACKNOWLEDGMENTS}

The authors thank Xingzhong Li for TEM assistance and Minglang Yan, Jian Zhou, and Yucheng Sui for their help in experiments. This work is supported by NSF, ONR, INSIC, NRI, and CMRA.

${ }^{1}$ C. P. Luo and D. J. Sellmyer, Appl. Phys. Lett. 75, 3162 (1999); C. P. Luo, S. H. Liou, L. Gao, Y. Liu, and D. J. Sellmyer, ibid. 77, 2225 (2000); M. L. Yan, H. Zeng, N. Powers, and D. J. Sellmyer, J. Appl. Phys. 91, 8471 (2002).

${ }^{2}$ B. Bian, K. Sato, and Y. Hirotsu, Appl. Phys. Lett. 75, 3686 (1999).

${ }^{3}$ T. Suzuki, T. Kiya, N. Honda, and K. Ouchi, J. Magn. Magn. Mater. 235, 312 (2001).

${ }^{4}$ T. Yang, E. Ahmad, and T. Suzuki, J. Appl. Phys. 91, 6860 (2002).

${ }^{5}$ R. Wood, IEEE Trans. Magn. 36, 36 (2000).

${ }^{6}$ S. Sun, C. B. Murray, D. Weller, L. Folks, and A. Moser, Science 287, 1989 (2000).

${ }^{7}$ H. Haberland, M. Karrais, M. Mall, and Y. Thurner, J. Vac. Sci. Technol. A 10, 3266 (1992).

${ }^{8}$ Y. Xu, Z. G. Sun, Q. You, and D. J. Sellmyer, International Conference on Fine Particle Magnetism, P-16, Pittsburgh, Aug. 13-16, 2002.

${ }^{9}$ D. J. Sellmyer, C. P. Luo, M. L. Yan, and Y. Liu, IEEE Trans. Magn. 37, 1286 (2001) 